\title{
Tecnologia e Update do Corpo no Cinema de Ficção Científica Contemporâneo
}

\author{
Technology and body update in the contemporary Sci-Fi cinema
}

Cristina Alves ${ }^{1}$

Artigo recebido em para publicação em out./2013 e aceito para publicação em jun./2014

\section{RESUMO}

De um estilo literário restrito a poucos aficionados, a ficção científica (FC) torna-se, nos dias atuais, uma área de interesse de pesquisadores de todos os campos do conhecimento, inclusive das ciências sociais, com foco na vida do homem moderno e a incidência cada vez mais forte da tecnologia em seu cotidiano. Através de uma breve análise das características e transformações pelas quais vem passando a literatura e o cinema de FC, bem como, da utilização de algumas obras icônicas como exemplos, buscamos demonstrar como esse gênero da literatura nos pode ser útil para compreender a relação do homem frente às mudanças que revolução tecnológica proporciona.

Palavras-chave: Tecnología. Técnica. Update do corpo. Ficção científica. Sociologia da técnica.

\begin{abstract}
A literary style restricted to a few enthusiasts, science fiction becomes, nowadays, a area of interest to researchers in all fields, including social sciences, interested in the life of modern man and the increasingly strong incidence of technology their daily lives. Through a brief analysis of the characteristics and transformations which comes through science fiction literature and cinema, as well by the use of some iconic works as examples we would like to demonstrate how this genre of literature can be useful in order to understand the relationship between man front the changes that technological revolution provides.
\end{abstract}

Keywords: Technology. Technic. Body update. Science fiction. Technical sociology.

\section{INTRODUÇÃO}

As novas formas de comunicação, a internet e o celular, entre outras milhares de novidades tecnológicas, pelas quais somos constantemente interpelados, alteraram o modo como nos relacionamos uns com os outros, modificaram os padrões culturais, aproximaram e distanciaram povos. As pesquisas e descobertas da tecnociência, da medicina genética e da neurobiologia afetaram definitivamente o modo como concebemos a saúde, a doença, o corpo, a vida, a morte. Um novo universo de possibilidades de criação, reprodução, construção e destruição se abre ao homem, tanto em relação ao mundo à sua volta quanto a respeito de si mesmo.

\footnotetext{
${ }^{1}$ Mestre pelo Núcleo de Pesquisa e Pós Graduação em Sociologia da Universidade Federal de Sergipe. E-mail: crys-allves@hotmail.com.
} 
Desde meados do século $\mathrm{XX}$, o corpo tem sido objeto de estudos mais atentos no âmbito das ciências sociais e tem adquirido maior importância e visibilidade, na medida em que nos dias atuais este tem sido manipulado, esquadrinhado e questionado com maior frequência. Pesquisas científicas abordam a temática da corporeidade tanto no intuito de alcançar um corpo perfeito como também com o objetivo de melhorá-lo técnica e maquinicamente.

Com o advento da internet e com a maior proximidade do discurso tecnocientífico do ambiente social, cria-se um imaginário no qual o corpo ocupa um lugar de destaque, seja em busca de uma transcendência do biológico para algo mais que humano, seja na perspectiva de torná-lo dispensável. Tal cenário é um reflexo da saída da ficção científica de uma posição subvalorizada no ambiente literário, para um patamar onde adquire alguma importância na compreensão das mudanças promovidas pelo rápido avanço das tecnologias.

Através de seus produtos culturais é que uma sociedade revela seu imaginário, seu modo de pensar, compreender e lidar com as mudanças na sociedade. Além disso, é através desses mesmos produtos que se dá o primeiro contato com as perspectivas da ciência moderna, mesmo quando isso acontece a partir de um cenário distante e fantástico. No caso da tecnociência, especificamente, esse imaginário vem à tona por meio das narrativas de FC. E, dentre estas, as cinematográficas, por seu apelo visual e por atingir um público bem mais vasto que a literatura, nos permitem ampliar o horizonte dos nossos pensamentos, na medida em que misturam ficção e elementos da realidade.

\section{O CORPO NA MODERNIDADE}

O corpo é o lugar onde percebemos com maior evidência as transformações sociais. Desde os costumes, passando pela moda e chegando às tendências de virtualização e ciborguização do homem encabeçadas pela cibercultura. As novas tecnologias aplicadas ao corpo querem transformá-lo num objeto remodelável, plástico, substituível, descartável, que possa ser transformado segundo as expectativas e desejos do indivíduo ou "usuário". O upgrade do corpo humano é um processo que visa adequar o homem ao ritmo acelerado e ao ambiente tecnicizado da sociedade atual. 
Durante muito tempo, prevaleceu a ideia de que o corpo era assunto para a biologia e a psicologia, visto que era concebido pela natureza tal e qual. Entretanto, a partir do início do século $\mathrm{XX}$, começa a esboçar-se com a psicanálise a ideia de que o corpo não é simplesmente um organismo biológico, mas também carrega marcas da sociedade e de sua história pessoal. Com isso nasce, nas ciências sociais, o interesse pelo assunto. Porém, somente a partir da década de 1960, é que se assume o desafio de localizar o corpo no pensamento sociológico (BATISTA, 2010).

O processo de modificação do homem pela técnica não é novidade. Na verdade, está presente desde que a espécie humana começou a construir ferramentas para facilitar a realização de seus objetivos e potencializar o alcance de seu agir no mundo. O que ocorre na modernidade técnica é uma aceleração exacerbada desse processo, alavancado pelo cada vez maior alcance do conhecimento que a ciência possui do corpo humano e do maior domínio do homem sobre as tecnologias informáticas. Para Santaella (2003), o processo de ciborguização, pelo qual passa o homem, nada mais é do que a continuidade do processo de saída deste da natureza, através da técnica.

Pensadores radicais do status do corpo na modernidade técnica falam de sua obsolência, um corpo que é carregado como um fardo pelo homem e que, com o desenvolvimento da tecnologia informática, telecomunicações e da neurociência, bem como outras ciências biológicas, tende a se transformar radicalmente, podendo inclusive ser substituído por peças cibernéticas, menos instáveis e perecíveis. Ou, numa concepção mais radical ainda, alguns preveem a substituição completa do corpo por um banco de dados e por ela anseiam, virtualizando assim a existência humana tendo em vista que as tecnociências encaram o pensamento do homem como um banco de dados que pode ser interpretado por código binário, tal qual um computador (RÜDIGER, 2006; SANTAELLA, 2003; SIBILIA, 2002). Nesta perspectiva a essência do homem estaria na mente e o corpo seria apenas 0 invólucro que a contém. E, nesse caso, seria modificável e substituível.

$\mathrm{Na}$ contemporaneidade, as mudanças advindas do âmbito da ciência e tecnologia passam a acontecer num ritmo cada vez mais acelerado, ficando cada vez mais evidentes no cotidiano. Isso se reflete no surgimento de manifestações culturais e artísticas voltadas para o universo científico, que se propõe a pensar, com 
maior liberdade que a ciência, as novidades tecnológicas e seus efeitos e consequências sobre a vida do homem.

Se observarmos como o homem se relaciona com seu corpo nos dias atuais, podemos com facilidade compreender essa relação como uma experimentação. Hoje o corpo é considerado um palco de transformações, um campo de experiências, que a ciência desvela para entender seu funcionamento e trabalha no sentido de potencializar, melhorar, curar, transformar e mesmo criar.

A ideia de que através das intervenções técnicas se possa chegar ao "corpo perfeito", seja ele modelado por exercícios físicos, dietas ou cirurgias estéticas é amplamente difundido pelos meios de comunicação, tornando-se o objetivo de muitos homens e mulheres que buscam, através de seu corpo, exteriorizar sua saúde e suas qualidades. Exemplo disso é que o Brasil figura entre os primeiros países na lista dos que mais realizam intervenções estéticas. Apenas nos primeiros meses de 2011, verificou-se um aumento de $60 \%$ na procura por implantes de próteses nos glúteos ${ }^{2}$, sem mencionar outras especialidades da cirurgia plástica. Segundo Le Breton, o corpo tornou-se um acessório, uma prótese, um kit, um objeto imperfeito, que necessita ser corrigido. O sucesso da cirurgia plástica atesta que de fato muda-se o corpo para mudar a vida (LE BRETON, 2003).

O gerontologista Aubrey De Grey acredita que a ciência está muito perto de alcançar a "cura" para a velhice, bem como de ser capaz de eliminar, por meio de tratamentos genéticos, todas as doenças. Segundo ele, os benefícios da ciência médica contemporânea possibilitarão o aumento exponencial da expectativa média de vida. Em entrevista à revista Veja em junho de 2011, De Grey afirma que "temos $50 \%$ de chances, com os avanços dos estudos a respeito da degenerescência das células, de estender a vida humana a 200 anos até 2030-2040”3. Entretanto, faz questão de frisar que não está em busca de uma fórmula para a imortalidade. Seu objetivo é estender a vida e erradicar as doenças do corpo humano.

Entretanto, ele não é o único, nem tampouco o primeiro disposto a anunciar as maravilhas que a tecnologia, supostamente, pode trazer para a qualidade de vida do homem. Um dos mais respeitados e conceituados nomes no campo da tecnologia é

\footnotetext{
${ }^{2}$ Revista Veja Edição 2239 - ano 44 - n॰ 42 (19 de outubro de 2011) - Especial: Projeto Verão.

${ }^{3}$ Revista Veja - edição 2221 - ano 44 - n 24 (15 de junho de 2011) - Especial: Longevidade.
} 
o inventor americano Ray Kurzweil ${ }^{4}$ que, dentre outras façanhas, previu nos anos 1980 o que seria a internet hoje.

Kurzweil acredita que a inteligência humana é a força mais poderosa do universo e que, graças a ela, em poucos anos a inteligência artificial chegará ao mesmo patamar da inteligência humana. Com isso, prevê que com o avanço exponencial da tecnologia "vamos transcender nossas limitações biológicas" ${ }^{2}$ e, em última instância, a ciência será capaz de num futuro muito próximo proporcionar ao homem a imortalidadel $^{6}$.

Os exemplos acima parecem saídos da ficção científica, no entanto, são muito reais e provocam e desafiam a imaginação e os limites da ciência. Mais que modelar e "melhorar" o corpo, as novas tecnologias prometem alçar o corpo à condição máquina: mais durável, mais eficiente, enfim, "[pretendem] alçar o corpo à altura da tecnologia de ponta e submetê-lo a uma vontade de domínio integral, percebendo-o como uma série de peças destacáveis e hibridáveis à máquina" (LE BRETON, 2003, p.46). O corpo humano natural torna-se a cada dia mais ultrapassado.

É interessante, entretanto, perceber que as declarações de alguns cientistas de peso das tecnociências parecem mais carregadas de ousadia que as narrativas de FC. Ray Kurzweil, com sua crença na transcendência e virtualização do homem, e Aubrey De Grey, com sua fé que a tecnologia nos fará viver por mil anos. "É como se a capacidade de fabulação que sempre caracterizou o mundo da arte e da ficção e que nos fazia conhecer universos e presentes paralelos à nossa realidade tivesse sido usurpada pelos novos tecnocientistas" (TUCHERMAN, 2006, p.87).

Resta então à ficção expressar a inquietação e a angústia do homem diante desse novo mundo de possibilidades, caracterizado quase sempre por ela de maneira distópica ${ }^{7}$ e descrente, quase como um alerta para o que pode estar para acontecer. A FC hoje, no lugar de proporcionar uma abertura para os prognósticos e possibilidades futuras - como é de seu caráter desde seu surgimento - se posiciona muito mais de modo a germinar uma desconfiança quanto a esse futuro maravilhoso que a tecnociência promete e que se encaminha para o que alguns autores

\footnotetext{
${ }_{5}^{4}$ Site oficial Raymond Kurzweil: http://www.kurzweilai.net/.

${ }^{5}$ Kurzweil In: Revista Veja - ed. 2221, ano 44, 15 de jun. 201, p. 146 - Especial Longevidade.

${ }^{6}$ Transcendent Man (Homem Transcendental), Robert Barry Ptolemy (diretor) - Ptolemaic Productions (2009/ documentário).

${ }^{7}$ A distopia na ficção científica caracteriza-se principalmente por isolar algumas categorias do desenvolvimento tecnológico destacar de forma exagerada seus aspectos negativos.
} 
caracterizam como uma ruptura antropológica. De um modo ou de outro, entretanto, as narrativas ficcionais nos ajudam a discutir o nosso presente em mutação.

\section{FICÇÃO CIENTÍFICA E AS REPRESENTAÇÕES DO CORPO MODIFICADO}

Desde seu surgimento, a FC se propõe a extrapolar os limites da ciência de seu tempo para explorar as possibilidades mais fantásticas da tecnologia, causando fascínio e apreensão tanto para leitores e expectadores quanto para os próprios personagens. Ao combinar a profundidade de subjetividade do humano, o uso da técnica para mudar a sociedade e o sonho de novos espaços em um tempo futuro, o pensamento moderno cria também as condições de surgimento da ficção científica (OLIVEIRA, 2003, p. 180).

Considerando esse gênero literário como mais do que simplesmente criador e propagador de fantasias, e levando em consideração que a FC se propõe desde o início a interrogar a cultura moderna, as novas formas de organização social que surgem e a posição do homem diante destas transformações, é possível, a partir das temáticas e da estética desse gênero narrativo, estabelecer algumas ligações entre a ficção e a realidade.

Nesse contexto, elementos chave e que por muito tempo figuraram como elementos característicos da FC se tornam menos frequentes e instigantes quanto o ciborg: o homem tecnicamente modificado, com vistas a alcançar um patamar de superioridade aos seus semelhantes ou de igualdade à máquina.

Ícone da cibercultura, o ciborg anuncia um futuro totalmente diverso da realidade que experienciamos. As promessas desse futuro ultrapassam as fronteiras da FC quando pensadores da ciência se apropriam dessa figura para compreender as transformações pelas quais passa o mundo contemporâneo, quando o homem faz a experiência da sua própria ultrapassagem (GALIMBERTI, 2006). Ciborg é um termo cunhado em 1960 por Manfred E. Clynes e Nathan S. Kline que denomina a junção de um organismo biológico a uma aparelhagem tecnológica, cibernética (cib=cibernética + org =organismo) e foi difundido e popularizado na literatura e no cinema cyberpunk, que teve seu advento na década de 80 .

A possibilidade, entre tantas outras, de mesclar o corpo humano à máquina ou a partes maquínicas configura um novo modo de encarar o homem, o corpo e a vida. 
Terminator - Salvation (2009) oferece um ótimo exemplo da mudança de percepção do indivíduo a partir do imbricamento homem-máquina. Num cenário onde homens e máquinas estão em guerra pelo controle do planeta, o aparecimento de um ciborgue, híbrido de homem e máquina, causa temor e desconfiança entre os humanos. Meio homem, meio máquina, Marcus Wright se declara humano, pensa, sente, age e reage como humano, mas tem partes cibernéticas e com isso traz em si parte do inimigo, não sendo por isso digno de confiança entre os humanos em guerra com as máquinas.

Deixando um pouco de lado o cenário devastador da guerra mostrada no filme e todo o seu caráter apocalíptico, ainda teremos o que aqui consideramos o ponto mais relevante que essa narrativa em especial desperta na discussão do corpo contemporâneo: a partir de que ponto do imbricamento do homem com as máquinas, ocorre uma ruptura antropológica e o homem torna-se outra coisa?

Entretanto, simbioses, manipulações genéticas e morfológicas dizem muito mais a respeito do corpo do homem que de sua mente e seu espírito. Para Le Breton (2003), a partir do momento que nos utilizamos da tecnologia para nos relacionar com o mundo e com o outro, fazendo uso de aparelhos celulares, internet e mesmo artefatos destinados a resolver deficiências físicas (marca-passo eletrônico) e potencializar capacidades (óculos de grau, aparelhos de surdez) nos tornamos ciborgue.

E ainda, se o corpo é algo plástico, completamente modelável e substituível, o mesmo não vale para a mente. A partir disso e considerando o cogito e a ideia de que a essência do homem está em sua mente, podemos com alguma certeza concluir que tais saltos antropológicos ou upgrades corporais concorrem no sentido mais de adaptar o corpo humano às imposições do dispositivo técnico ${ }^{8}$, com sua exigência de funcionalidade e sua tendência de aceleração e artificialização dos processos, do que realmente alterar ou mesmo extinguir o homem.

Além do ciborgue, largamente explorado pela FC, a manipulação genética e morfológica do corpo para melhorar o homem e a sociedade e garantir-lhe mais tempo de vida ou substituí-lo por uma versão virtual que dispensa preocupações com o corpo é também bastante explorada quando se trata de pensar as

\footnotetext{
${ }^{8}$ Brüseke (2006) interpreta a noção de Gestell como dispositivo técnico: um conjunto de elementos e características que, reunidos, incorporam e ampliam a noção de técnica formulada por Heidegger e nos ajuda a compreender o sentido da técnica moderna em sua essência.
} 
transformações que o domínio tecnológico traz para a vida humana e suas consequências, desde as positivas e aparentemente inofensivas às mais dramáticas e radicais. Nesse sentido, o maior ícone do gênero é o distópico Admirável Mundo Novo, escrito por Aldous Huxley e publicado nos EUA em 1931.

Num espírito um tanto quanto sombrio e sobrecarregado de um tom deveras negativo, o livro retrata uma sociedade do futuro estratificada e dominada pela tecnologia em todos os seus aspectos, desde a concepção até a morte do indivíduo, em que os grandes avanços científicos proporcionaram um grau elevado de manipulação genética e estabilização social.

Admirável Mundo Novo traz, de forma muito clara, as preocupações e receios de seu autor em relação ao crescente alcance dos meios técnicos, preocupação que se torna mais latente se levarmos em consideração que a época em que o livro foi escrito é marcada pelos horrores da I Guerra Mundial. Em 1946 - depois de mais uma grande guerra - Huxley escreve um novo prefácio para sua obra. Nele fica mais que evidente que essa desconfiança sombria e esses receios continuam vivos na cabeça do escritor que, mesmo fazendo ressalvas à sua narrativa, mantém seu argumento de que o poder tecnocientífico tende a suprimir a liberdade do homem sob um ideal de segurança e estabilidade. A estabilidade é resultado de vários métodos de condicionamento físico e psicológico ao longo da vida. "O tema de Admirável Mundo novo não é o avanço da ciência em si; é esse avanço na medida em que afeta os seres humanos" (HUXLEY, 2009, p.15).

A obra de Huxley inspirou também algumas produções cinematográficas, entre elas Gattaca (1997), que apresenta uma sociedade onde o conhecimento completo do código genético e o controle dos meios que possibilitam alterá-lo e modificá-lo permite que os progenitores escolham as características dos seus filhos, além, é claro, de prevenir os eventuais problemas de saúde que eles possam vir a ter.

O filme conta a história de um homem concebido sem predeterminações genéticas, tentando superar os limites que the são impostos por uma sociedade geneticamente controlada. Para realizar seu sonho de trabalhar na empresa GATTACA, ele se submete às mais radicais e dolorosas transformações corporais para se adaptar àquele mundo onde o DNA determina a vida do indivíduo e ser biologicamente natural não é mais suficiente.

A sociedade descrita em Gattaca é, tal como a descrita por Huxley, marcada pela busca de uma sociedade ideal e hegemônica. O sucesso social e profissional 
do indivíduo depende diretamente das características escolhidas para ele por seus progenitores. Aqueles que são concebidos de modo tradicional são marginalizados por essa sociedade, ficando responsáveis pelos trabalhos mais simples e tornandose quase invisíveis e sem importância aos olhos dos "predeterminados".

O determinismo biológico que o desenvolvimento das ciências da medicina impõe acaba por gerar uma nova eugenia, não mais baseada na raça, como aquela almejada pelo nazismo, mas na carga genética do indivíduo, que acaba por definir sua identidade e se torna seu ingresso para o mundo social.

A manipulação genética também é explorada em $A$ llha (2005), filme baseado na novela homônima de Aldous Huxley. A estória se passa numa colônia de clones criados para fornecer "partes sobressalentes" para seus originais, tais como órgãos para transplante. Servindo de incubadora, os clones são usados também para gestar as crianças de seus originais.

Os clones, entretanto, não tem consciência de que não são os indivíduos originais, e acreditam que o planeta foi dizimado por uma catástrofe ecológica e que o único lugar seguro para se viver, além da própria colônia, é a ilha que dá nome ao filme. A colônia entra em colapso quando em um desses clones começam a emergir as "lembranças" da sua matriz e iniciam-se questionamentos acerca da sua origem e sua presença naquele lugar. O clone começa então a procurar respostas e acaba por descobrir que ele e todos ali são clones e que não há ilha alguma como também não houve nenhuma catástrofe ambiental.

A ciência mostra que tem a capacidade para ultrapassar os limites biológicos e modificar a relação que o homem tem com seu corpo. Seja por proporcionar-lhe um "depósito" de peças sobressalentes para reposição, como se o indivíduo fosse uma máquina, seja por levantar algumas questões acerca dos limites dessas ações. A colônia é um projeto secreto e exclusivo, realizado sem conhecimento do governo ou do grande público. O preço de um clone é altíssimo, tornando-se um produto para poucos privilegiados. Quando dois desses clones fogem da colônia e um deles encontra sua matriz, entra em discussão o dilema ético que envolve criar pessoas que não são tratadas como tal, mas como mercadoria, depósito de material que, após cumprir seu objetivo, simplesmente deixam de existir.

No mundo real, ao menos aparentemente, a dinâmica da medicina genética é bastante diferente, mas encontramos alguns pontos de confluência, apesar de sutis. Não estamos pondo em debate a ideia de clonar seres humanos, para que se tenha 
um duplo, ou uma reserva, mas o desenvolvimento de terapias com base na clonagem de partes do próprio indivíduo, que hoje já é possível e que se concretizado acabaria com as filas de espera para transplante de órgão. Hoje, a ciência já é capaz de criar um novo órgão para o paciente a partir de suas próprias células, se necessário for.

Em ambos os filmes torna-se claro que tanto as perspectivas quanto os desafios desse "avanço" tecnológico não estão presos à produção intelectual ou científicotecnológica, mas atingem toda a sociedade e levanta questionamentos acerca do que está por vir. As produções culturais surgidas sob o signo da tecnologia que transforma radicalmente a vida do homem são, em sua maioria, não só dotadas das promessas de um novo mundo, mas também possuem uma grande carga crítica a respeito das novas tecnologias e, principalmente, são preocupadas com os parâmetros éticos que conduzem esse caminho da humanidade.

Observar as possibilidades da tecnociência para o futuro do homem sob os olhos da ficção nos permite pensar com mais liberdade e ousadia as prováveis consequências das ações humanas na atualidade. Embora o futuro não seja passível de uma previsão inteiramente confiável, temos a possibilidade de indagar os limites daquilo que nos é proposto hoje pela técnica e pela ciência. "Na ficção científica o homem rompe o eixo que o ligava à ética, e esse desligamento humano dos valores morais implica sociedades desajustadas e, muitas vezes, catastróficas, refletidas pelo gênero" (BALDESSIN, 2006, 42).

As técnicas ou a tecnologia desenvolvida e aplicada ao corpo concorrem não apenas para o seu esquecimento, mas têm como caminho alternativo a construção de um corpo perfeito (upgrade do humano). Cirurgia plástica, próteses, manipulação genética, trabalham numa dinâmica que pretende levar a "cura" da velhice, das doenças, prolongar a vida indefinidamente e abre espaço para pensar o fim da morte - o mais antigo desejo do homem.

\section{CONSIDERAÇÕES FINAIS}

O acelerado desenvolvimento tecnológico nos leva a pensar sobre o que seria o homem no século XXI. Pesquisas sobre inteligência artificial, biocibernética, nanotecnologia, realidade virtual, protética e manipulação genética apresentam resultados cada vez mais impressionantes e tão próximos da FC que nos parece 
estarmos entrando numa nova realidade, em que um novo tipo de humanidade se desenvolve auxiliado pela tecnologia.

Comparar o corpo humano à máquina e almejar que estes tenham sua eficiência e funcionalidade, figura entre os pilares da cultura tecnológica propagada principalmente pela internet. Entretanto, mesmo explorando ao máximo e extrapolando os limites do que a ciência hoje considera plausível, crer que a tecnologia será capaz de eliminar, ao longo do seu desenvolver, os males causados por ela própria, nos parece um tanto quanto precipitado e mesmo irresponsável, como afirma Jonas (2006).

O nosso tempo nos oferece liberdade de escolha como nunca antes, mas também nos lança num estado de incerteza que nunca foi tão angustiante. A ambivalência da ação humana sobre o mundo e seu corpo, levanta mais questionamentos que certezas, sobre as consequências reais das transformações que ocorrem no tempo em que vivemos. $O$ anúncio de uma ruptura antropológica, baseada no desenvolvimento da tecnociência, parece factível e ainda assim difícil de pensar como algo tão próximo. Factível, na medida em que levamos em consideração a contingência do homem, que ganha evidência na modernidade técnica. E, por outro lado, difícil pela transformação radical que propõe ao corpo e o imaginário que temos sobre ele.

Contudo, as técnicas aplicadas ao corpo apontam não para um destino único, mas demonstram uma abertura cada vez maior no horizonte de possibilidades. Destas, as que a ciência médica apresenta para a solução de problemas graves parecem as mais promissoras e plausíveis. Ainda assim, os arautos da tecnociência parecem ignorar que vivemos numa época com uma lógica de mercado que influencia e determina o acesso a essas novidades. Anunciar um futuro promissor para a humanidade, amparado pela tecnologia, sem levar em conta os determinantes econômicos, revela certa ingenuidade e irresponsabilidade.

Não há como saber qual o futuro do corpo humano: geneticamente melhorado, unido simbioticamente a máquinas, abolindo o corpo e preservando a mente em ambientes virtuais e bancos de dados ou sendo simplesmente humano (mesmo que essa possibilidade pareça não figurar na discussão tecnocientífica). A preocupação no que concerne à responsabilidade pelas intervenções técnicas do homem no mundo e no seu corpo não deve escapar ao horizonte das descobertas e revoluções 
tecnocientíficas. Menos ainda do debate intelectual acerca do que é possível, viável, ético e desejável para o homem enquanto espécie.

\section{REFERÊNCIAS BIBLIOGRÁFICAS}

BALDESSIN, Marceli G. S. A ficção científica como derivação da utopia. 2006. 163 f. Dissertação (Mestrado em História e Teoria Literária) - Instituto de Estudos da Linguagem, Universidade Estadual de Campinas, São Paulo.

BATISTA, Micheline Dayse Gomes. Second Life: corpo e identidade no mundo virtual. 2010. 176 f. Dissertação (Mestrado em Sociologia) - Universidade Federal de Pernambuco (UFPE), Recife - PE.

BRÜSEKE, Franz J. A Modernidade Técnica. Revista Brasileira de Ciências Sociais. V. 17 n. 49. Jun. 2002. P.135-144. São Paulo: ANPOCS

BRÜSEKE, Franz J. O Dispositivo Técnico. In: Modernidade Técnica: contingência, racionalidade e possiblidade. Florianopólis: Insular, 2010.

GALIMBERTI, Umberto. Psiche e Techne: o homem na idade da técnica. São Paulo: Paulus, 2006.

HUXLEY, Aldous. Admirável Mundo Novo. São Paulo: Globo, 2001.

JONAS, Hans. O princípio responsabilidade: ensaio para uma ética da civilização. Rio de Janeiro: Contraponto - Ed. PUC, 2006.

Le BRETON, David. Adeus ao corpo: antropologia e sociedade. Campinas: Papirus, 2003.

OLIVEIRA, Fátima R. Ficção Científica: uma narrativa da subjetividade homem máquina. Revista Contracampo - Vol. 09, $\mathrm{n}^{\circ}$ 0, 2003. Disponível em: http://www.revistas.univerciencia.org/index.php/contracampo/article/view/36/35

OLIVEIRA, Fátima R. Como a ficção científica conquistou a atualidade: tecnologias de informação e mudanças na subjetividade. Revista Brasileira de Ciências da Comunicação - vol. XXVIII, n² 2, julho/dezembro 2005.

RÜDIGER, Francisco. Cibercultura e pós-humanismo: exercícios de arqueologia e criticismo. Porto Alegre: EDIPUCRS, 2008.

SANTAELLA, Lucia. Culturas e artes do pós-humano: da cultura das mídias à cibercultura. São Paulo: Paulus, 2003.

SIBILIA, Paula. O homem pós-orgânico - corpo, subjetividade e tecnologias digitais. Rio de Janeiro: Relume Dumará, 2002. 
TUCHERMAN, leda. A ficção científica como narrativa do mundo contemporâneo. Revista Com Ciência, № 59 - Outubro /2004.

TUCHERMAN, leda. Fabricando corpos. Revista Comunicação, Mídia e Consumo, n 7 - Jul. 2006. Pp. 77-92.

FILMES:

A llha / The Island. EUA: Warner Bros, 2005. Dir.: Michael Bay. 136 min.

Gattaca - Experiência Genética / Gattaca. EUA: Columbia Pictures / Sony Entertainment Pictures, 1997. Dir.: Andrew Niccol. 112 min.

Exterminador do Futuro - A Salvação / Terminator - Salvation. EUA: Warner Bros, 2009. Dir.: McG. 115 min. 